\title{
A NEW PLATYCHOLELS.
}

BY H. C. FALL.

While collecting at Lake Tahoe in the summer of 1897 , a number of specimens of Platycholeus leptinoides were taken by the writer. Among these was a single female specimen of duller surface lustre, which was set apart to a wait the possible turning up of a similar male. During the past summer (1909) Dr. Fenyes took a good series of Platycholeus of both sexes, all alike, and all precisely similar to my dull female taken twelve years before. An examination of the male confirms my suspicion that we have here to do with a species quite distinct from leptinoides, and enables me to present a comparative description.

Platycholeus opacellus n. Sp.

Of the same size and color as leptinoides, from which it differs in its duller surface Instre, the pronotum being only feebly shining and the elytra quite opaque. The elytra are also less pointed behind; the antennae less slender, the joints generally less elongate, the sixth but little longer than wide, the cighth slightly transverse. Secondary sexmal characters of the legs less marked, the front tibiae of the male less suddenly dilated, the hind tibiae quite devoid of denticles along the inner margin. In leptinoides the entire upper surface is rather strongly shining, the elytra more acutely pointed behind, antennae nore slender, joint 6 nearly twice as long as wide, $S$ a little longer than wide.

The minute denticulation along the inner margin of the hind tibiae in the male of this species seems to have been overlooked by both Crotch and Horn. As observed by Horn, the middle tibiae are quite strongly arcuate in both sexes of lepitnoides. This holds in opacellus, but the arenation is somewhat less strongly and more even.

My specimens were taken in rotten wood in which termites were present. According to a published note by Mr. Schwarz, "specimens were obtained by Mr. H. G. Hubbard in July, 1891, at Lake Tahoe in a colony of Termopsis angusticollis, within the stump of a large pine tree; and other specimens found by Mr. Koebele in California with the same host are in the National Museum." This certainly would seem to prove conclusively that Platycholeus is 'Temitophilous. Dr. Fenyes however informs me that all his examples were found with a rather small yellowish brown ant under bark, an apparently sure indication of Myrmecophilous habits. While it is not impossible that Platycholeus may occur with both ants and Termites, the fact would be a very remarkable one, and further investigation may prove that in one case or the other the association was accidental. 

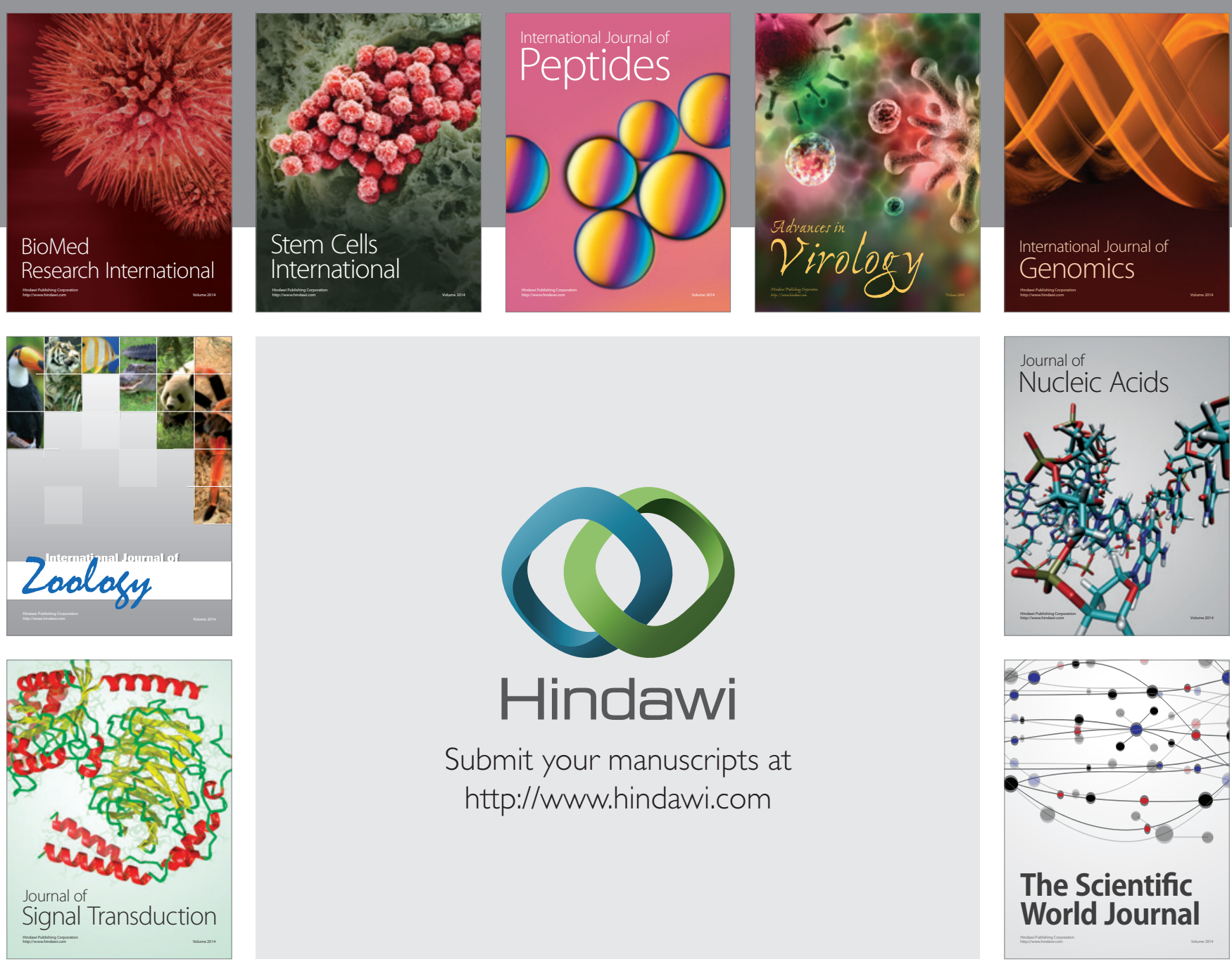

Submit your manuscripts at

http://www.hindawi.com
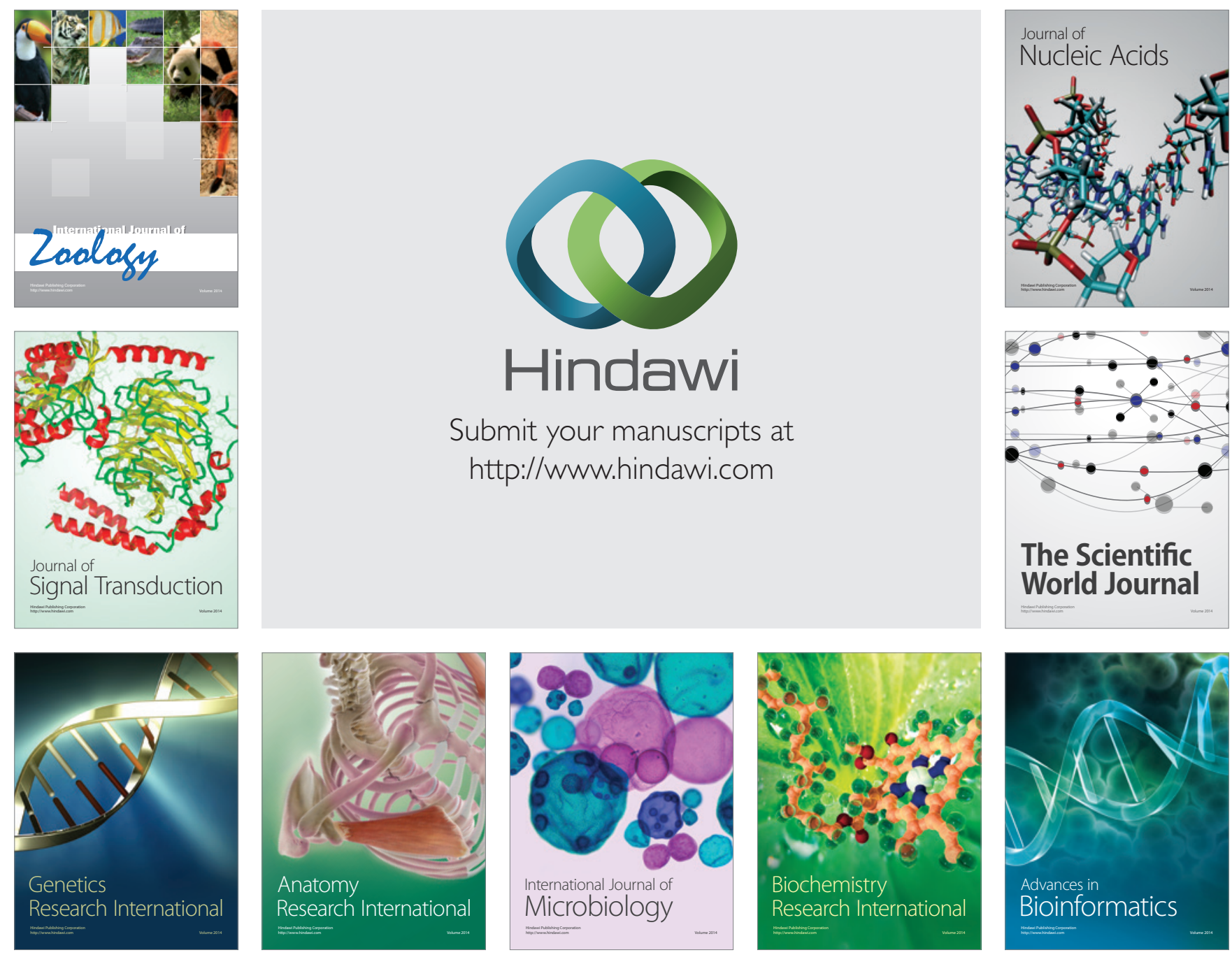

The Scientific World Journal
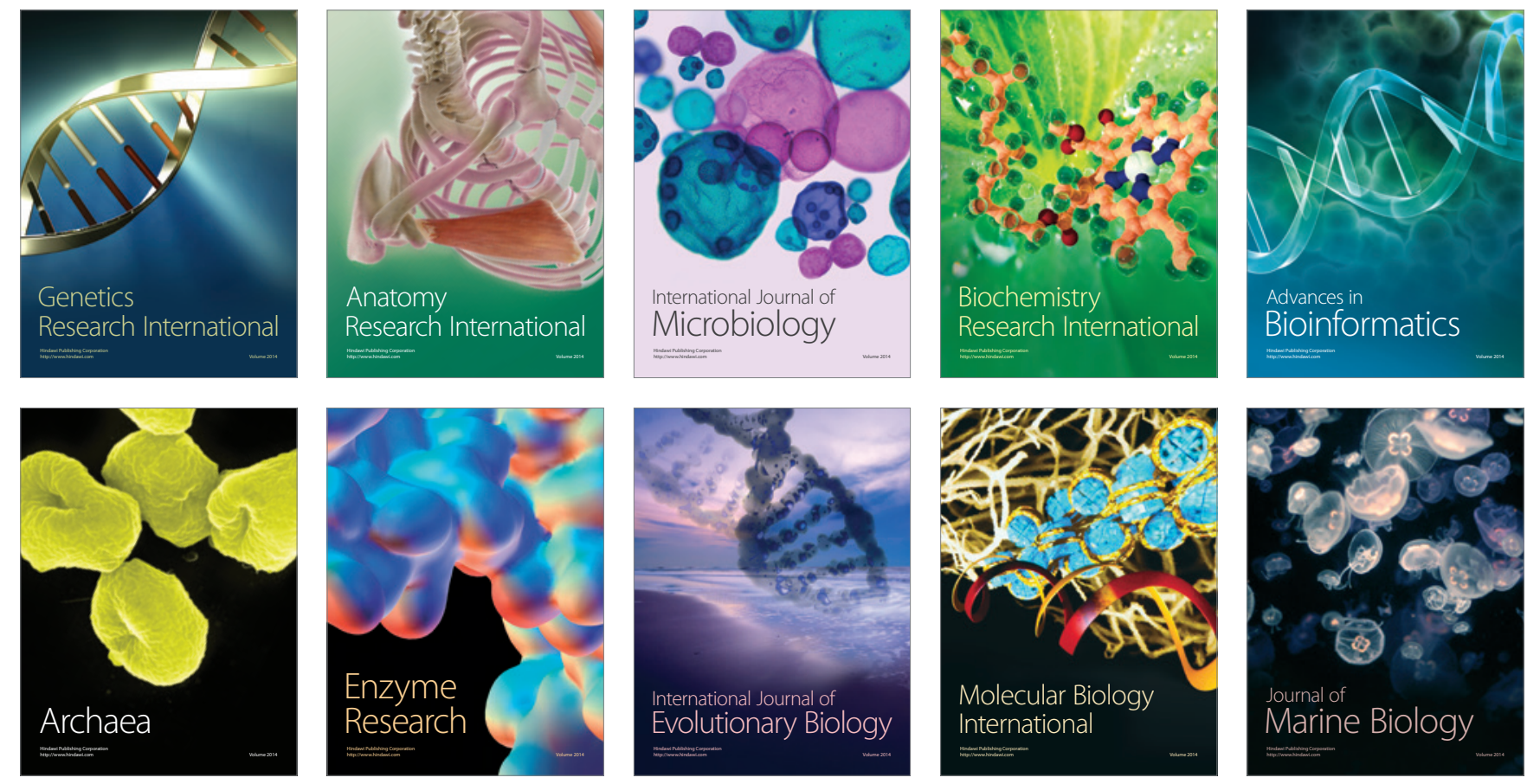